\title{
Jornalismo Literário: a realidade de forma autoral e humanizada
}

\author{
Monica Martinez
}

\section{Resumo}

O Jornalismo Literário é um gênero fronteiriço, que tira partido das técnicas literárias e dos elementos básicos jornalísticos, como levantamento de informações, para produzir um texto bem apurado e escrito. A história do Jornalismo Literário começa bem antes de sua fase mais famosa, o Novo Jornalismo norteamericano dos anos 1960, com o trio formado por Gay Talese, Truman Capote e Norman Mailer. É que as origens dessa escola remontam aos escritores europeus do século 17, como Daniel Defoe. No Brasil, marcos são Euclides da Cunha e João do Rio, pseudônimo do multimídia da época Paulo Barreto. A revista Realidade e o Jornal da Tarde continuam referências, num cenário que tem se aberto com a criação de revistas com Brasileiros e Piauí, além de sites. Os livros-reportagem seguem sendo o lugar onde a literatura e o jornalismo mais se encontram.

Palauras-chave:

Comunicação, Jornalismo, Jornalismo Literário, História do Jornalismo

\section{Literary Journalism: reality on an authorial and humanized basis}

\section{Abstract}

Literary journalism is a borderline gender that aims the production of creative writings based both on literary and journalistic techniques. The movement became worldwide known back in the 1960's due to the innovative work of North American reporters such as Gay Talese, Truman Capote, and Norman Mailer. However, its roots are much older, going as deep as the 17th century European writer Daniel

Sobre 0 autora

Doutora em Ciências da Comunicação pela Escola de Comunicações e Artes da Universidade de São Paulo, é pos-doutoranda do Programa de Pós-Graduação da Universidade Metodista de São Paulo. martinez.monica@uol.com.br Defoe (1660-1731). In Brazil, the form can be retraced to the journalists Euclides da Cunha (1866-1909) and João do Rio (1881-1921), Paulo Barreto's fictitious name. Realidade magazine and Jornal da Tarde are still media references, but new publications, specially Brasileiros and Piaui magazines, besides websites and non-fiction books, are helping to develop the genre.

Key words:

Communication, Journalism, Literary Journalism, Journalism History 
Seja na teoria ou na prática, a história do Jornalismo Literário tem todos os elementos de uma boa narrativa. A começar, pelo conflito. Há quem seja arrebatado por esse gênero, que agrega técnicas literárias às boas práticas jornalísticas para produzir textos informativos e cativantes. Verdade seja dita, há também quem o ache arte de escritores frustrados, que tiveram de ganhar a vida nas redações.

Com todo o respeito pelos defensores dessa opinião, é necessário frisar que muitas vezes os oponentes mais ferozes do Jornalismo Literário desconhecem de fato o que ele é. Cá entre nós, há vários adversários da prática que se renderam aos seus encantos quando se permitiram o prazer de conhecê-lo melhor.

É importante ressaltar que há também ótimos profissionais que não estão nem aí para essas argüições acadêmicas, que querem mais é sujar os pés na rua - o verdadeiro lugar de repórteres se formos espertos e darmos ouvido a jornalistas do quilate de Ricardo Kotscho. Aliás, daqui para frente, será usado o termo leitores para simplificar, mas quando se deparar com ele entenda telespectadores, ouvintes, internautas, audiência, enfim, todo e qualquer receptor das mídias jornalísticas. Afinal, embora mais evidente nas publicações impressas, o Jornalismo Literário se aplica e pode ser encontrado em todas elas.

Francamente não importa o lado que você está, seja na defesa, no ataque ou no meio de campo do Jornalismo Literário JL daqui em diante. Vital é abrir-se para entender o que o JL representa e para as vantagens que pode trazer para melhorar produção textual como um todo, da satisfação pessoal de quem o produz ao prazer de quem o lê.

\section{Como contar uma boa história}

Isso posto, vamos às pedras fundamentais do JL. E aqui se começa a esclarecer um equívoco: a de que o gênero surge nos anos 60 do século passado com o Novo Jornalismo. Apesar de todo o mérito que tiveram - e vamos explicá-lo mais à frente -, o fato é que a invenção não é um dos itens da longa e honrosa lista de créditos dos jornalistas americanos.

A saga do Jornalismo Literário começa muito tempo antes. Ouso até dizer que ela começa antes da escrita - e já me explico. Como toda boa narrativa, o JL presta muito mais atenção do que o jornalismo tradicional ao uso da oralidade, ou seja, à forma com que as pessoas expressam seus pensamentos, sentimentos e suas ações, enfim, sua forma de ver e de se relacionar com o mundo. Não seria incorreto, sob este ponto de vista, dizer que seus primórdios remontam à aurora da civilização. Tempo em que o ser humano se deu conta de que era finito e que, para lidar com o irremediável fato de sua mortalidade, começou a se questionar,
O JL presta muito mais atenção do que o jornalismo tradicional ao uso da oralidade, ou seja, à forma com que as pessoas expressam seus pensamentos, sentimentos e suas ações 
pensar, simbolizar e, sobretudo, comunicar suas inquietações e descobertas sobre essas questões que continuam nos intrigando até hoje, como a origem da vida, de onde viemos, para onde vamos, quem somos...

No campo do pensamento mítico, o JL tem em comum com os primeiros contadores de histórias a riqueza imagética, isto é, a capacidade de tecer narrativas com símbolos, metáforas e imagens que são de fácil compreensão para todos. Assim, em vez de gastar linhas e linhas explicando que tal político age, digamos, sem escrúpulos, pode-se dizer que o sujeito é uma raposa. Uma pequena palavra, mas com conteúdo tão abrangente que até uma criança a entende.

\section{Preto no branco}

Deixando para trás as pinturas rupestres e as fogueiras nas quais os xamãs usavam suas visões para orientar o futuro da tribo, passamos da transição da fase oral para a escrita. Com ela, muito da magia que cercava as histórias se perde. Mas há ganhos, como o amor ao conhecimento que permeia o Jornalismo Literário. Essa ligação o aproxima da Filosofia, enquanto a área humana que buscou, inicialmente, refletir sobre os fenômenos da Natureza e, mais tarde, o papel do ser humano na compreensão da realidade.

Do ponto de vista científico, um dos maiores saltos tecnológicos da civilização ocorre no século XV, quando o alemão Johann Gutemberg - inspirado nas prensas de uvas para o fabrico de vinho - inventou a prensa que possibilitaria a imprensa. Hoje é até difícil para nós imaginar a revolução que a impressão do livro de 74 páginas chamado Juizo Final (Weltgericht, no original) causou. Mas basta assistir ao filme O Nome da Rosa, com Sean Connery, baseado no livro homônimo de ficção do semioticista italiano Umberto Eco, para perceber o trabalho cuidadoso, custoso e, sobretudo, lento de copiar manuscritos à mão e margeá-los com belas iluminuras, a que muitos monges dedicavam a vida. Ainda que pese o fato que na época havia pouca gente alfabetiza$\mathrm{da}$, em geral pertencente às comunidades religiosas, a invenção da imprensa fez maravilhas para disponibilizar o conhecimento que levaria centenas de anos para ser aperfeiçoada, com o advento da internet.

Graças à tipografia, que acelera e barateia o processo de reprodução, a escrita, a leitura e, consequentemente, o acesso ao saber se populariza na Europa renascentista. Em cinqüenta anos, passou-se dos livros aos jornais e daí à implantação da imprensa foi um pulo. Até a consolidação do jornalismo, durante a Revolução Industrial do século XIX, os jornalistas não raro transitavam tanto pela plataforma livro quanto pela formada por jornais e
Até a consolidação do jornalismo, durante a Revolução Industrial do século XIX, os jornalistas não raro transitavam tanto pela plataforma livro quanto pela formada por jornais

e magazines 
magazines. Se na primeira escreviam como e o que queriam, nas redações ganhavam o sustento das famílias e se tornavam conhecidos do público. Parceria feita até hoje.

Por isso, autores como o norte-americano Normam Sims, professor do Programa de Jornalismo do Departamento de Comunicação da University of Massachusetts Amherst, sugerem que o jornalismo literário inspira-se nos escritores do século 17 como o londrino Daniel Dafoe (1660-1731). Mais conhecido por seu Robinson Crusoe, Dafoe publicou em 1722 O Diário do Ano da Peste, livro onde descreve minuciosamente a epidemia de peste bubônica que vitimou, segundo o escritor, 100 mil pessoas na capital inglesa em 1665.

"We had no such thing as printed newspapers in those days to spread rumours and reports of things", explica Defoe no primeiro parágrafo da obra, relatando que em setembro de 1664 não havia jornais para espalhar rumores ou reportar coisas. "But such things as these were gathered from the letters of merchants and others who corresponded abroad, and from them was handed about by word of mouth only; so that things did not spread instantly over the whole nation, as they do now", completa, lembrando que poucos anos depois não se dependia mais de cartas de mercadores e outros correspondentes estrangeiros ou de relatos orais para se saber das novidades.

Já no século XVII Defoe se esmera em registrar os fatos - usa tabelas de números de óbitos - com técnicas do escritor, tratando literariamente as cenas e usando diálogos. Um pouco mais tarde, já no século XIX, a transição do movimento literário romântico para o realista, que desejava mostrar o ser humano não em sua versão idealizada, mas imerso na vida como ela é, incita os escritores do período a mergulharem no cotidiano para trazerem elementos para sua obra ficcional. Nesse contexto, os protagonistas deixam de ser heróis para surgir como pessoas comuns, com altos e baixos, problemas e soluções. A adúltera Emma, protagonista de Madame Bovary, do francês Gustave Flaubert (1821-1880), inaugura o movimento, numa transição tão forte do romantismo que levou seu autor a julgamento por ter ofendido os costumes da época.

Também da França, um cronista memorável de seu tempo foi Honoré de Balzac (1799-1850), que descrevia seus personagens física e psicologicamente com precisão cirúrgica. Do conjunto de sua obra - entitulada Comédia Humana, reunião de mais de 90 contos e romances - destaca-se Eugênia Grandet, que narra a paixão de uma jovem provinciana, filha de agricultor que enricara a custa de trabalho duro, pelo primo parisiense, aristocrático e falido: "Carlos levou consigo, pois, o mais bonito traje de caça, o mais bonito fuzil, o mais bonito punhal, a mais bonita bainha de Paris" (Balzac, 1981: 47-48).
No século XIX,

a transição do

movimento literário romântico para

o realista, que desejava mostrar

o ser humano não em sua versão idealizada, incita os escritores a mergulharem no cotidiano para trazerem elementos para sua obra ficcional 
Longe de enfileirar a esmo itens, como uma lista de supermercado, a descrição dos artigos trazidos na bagagem de Carlos Grandet permite ao grande romancista caracterizar melhor o personagem, bem como seus hábitos e costumes: "Trouxe seus pequenos nadas de dândi, sem esquecer um gracioso jogo de escrivaninha dado pela mais amáveis das mulheres, pelo menos para ele, uma grande dama a quem chamava Anete, e que viajava maritalmente, tediosamente, pela Escócia, vítima de certas suspeiats às quais fora forçada a sacrificar momentaneamente sua felicidade; e mais uma quantidade de lindo papel para lhe escrever uma carta por quinzena" (idem).

No campo da não-ficção, Balzac escreveu Os Jornalistas (Ediouro), uma crítica contundente e feroz da imprensa do século XIX. Do outro lado do canal da Mancha outro escritor-jornalista que viveu no mesmo período foi tão genial quanto o francês, ajudando a introduzir o realismo social no jornalismo e na literatura praticados durante a era vitoriana. Trata-se de Charles Dickens (1812-1870), autor que, por ter vivido no auge da revolução industrial, na época em que o reino britânico era o maior império já visto no planeta, optou por abordar gente comum que vivia em condições duras da vida, como as crianças trabalhadoras da classe operária inglesa, caso de Oliver Twist (1837-1839).

De particular interesse para o Jornalismo Literário é seu livro Sketches by Boz (1836), literalmente Esboços de Boz, sendo seu pseudônimo no jornal Morning Chronicle (ele chegou a ser diretor do Daily News em 1846). Traduzida para o português pelo professor de jornalismo paulista Marcello Rollemberg, Retratos Londrinos (Record) tem título que ilustra bastante bem o espírito da obra. Em A Noite nas Ruas, de 17 de janeiro de 1836, fica evidente a capacidade de descrição de Dickens sobre as ruas londrinas no inverno: "Nos subúrbios, o jovem vendedor de bolinhos toca a sineta enquanto caminha pela rua estreita em ritmo mais vagaroso do que gostaria. A Sra. Macklin, do número 4, abre logo a pequena porta da casa e grita com toda força: "Bolinhos!" (Dickens, 2003: 79).

Ao continuar descrevendo a cena, Dickens - com sua notável habilidade de observador - convida o leitor a mergulhar nela: "Ao mesmo tempo, a senhora Walker, do número 5, coloca a cabeça para fora da janelinha da porta e também grita: "Bolinhos!"Assim que a Sra. Walker deixa a palavra escapar dos lábios, a Sra. Peplow, do outro lado da rua, já vai perdendo seu filho de vista. O jovem Peplow sai em disparada rua abaixo, com uma velocidade que apenas bolinhos amanteigados podem inspirar." (Dickens, 2003: 80).

Outra de suas obras de não-ficção, American Notes for General Circulation (Penguin Books), traz de forma bastante viva e envolvente o relato em primeira pessoa de sua viagem ao
Charles Dickens por ter vivido no auge da revolução industrial, na época em que o reino britânico era o maior império já visto no planeta, optou por abordar gente comum que vivia em condições duras da vida 
Mundo Novo em 1842. Em tradução livre da autora: "Nunca me esquecerei do $1 / 4$ de seriedade e $3 / 4$ de surpresa com os quais, na manhã de 3 de janeiro de 1842, abri a porta e coloquei minha cabeça dentro da cabine do vapor Britannia, de 12 toneladas, com destino a Halifax e Boston, carregado de correspondência de sua majestade". Mesmo em sua obra ficcional, Dickens tirava partido de seu treino jornalístico, como em Nicholas Nickleby, onde chega a visitar estabelecimentos de ensino para retratar com fidelidade os apuros pelos quais passam os órfãos que são temporariamente tutorados pelo protagonista.

Algumas décadas mais tarde, outros jornalistas se destacariam, notadamente em coberturas de guerras. É o caso do norte-americano John Reed (1887-1920), formado por Harvard e correspondente da Metropolitan, autor de México Rebelde (Civilização Brasileira), sobre a revolução mexicana de 1910, Guerra dos Bálcãs (Conrad), sobre a Primeira Guerra Mundial na Europa, e Dez Dias que Abalaram o Mundo (Global), sobre a revolução bolchevique na Rússia de 1917. Reed provavelmente teria continuado a escrever de sua forma comprometida e apaixonada não tivesse morrido de tifo aos 33 anos.

\section{A experiência brasileira}

Há dois autores que se destacam na história do Jornalismo Literário em terras brasileiras. O primeiro é, sem dúvida, o engenheiro Euclides da Cunha (1866-1909), que cobriu a insurreição de Canudos para o jornal O Estado de S. Paulo em 1897. Pelos cinco anos seguintes, aproveitou o material excedente para escrever Os Sertões, lançado em 1902. Republicano, Cunha parte de São Paulo acreditando na idéia comum de que o movimento pretendia restaurar a monarquia.

Ao chegar ao sertão baiano, porém, descobre uma realidade bem diversa da divulgada no Sudeste do país. Os "perigosos" insurgentes eram na realidade humildes agricultores, excluídos social e economicamente que, em meio a latifúndios, desemprego e seca inclemente, acreditam numa salvação milagrosa proposta pelo messias da sua época, Antônio Vicente Mendes Maciel (1830-1897), mais conhecido por Antonio Conselheiro. A ação do líder carismático da pequena comunidade às margens do rio Vaza Barris, que acolhia também os ex-escravos, não agradam clero, fazendeiros nem Estado. As elites organizam quatro expedições militares até sua morte, em 1897.

... Chegam à uma hora em grande número novos prisioneiros - sintoma claro de enfraquecimento entre os rebeldes. Eram esperados. Agitara-se pouco depois do meio-dia uma bandeira branca no cento dos últimos casebres e os ataques cessaram imediatamente do nosso lado. Rendiam-se, afinal. Entretanto não soaram os clarins. Um grande silencio avassalou as linhas e o acampamento.
Mesmo em sua obra ficcional, Dickens tirava partido de seu treino jornalístico, como em Nicholas Nickleby, onde chega a visitar estabelecimentos de ensino para retratar com fidelidade os apuros pelos quais passam os órfãos 
A bandeira, um trapo nervosamente agitado, desapareceu; e, logo depois, dois sertanejos, saindo de um atravancamento impenetrável, se apresentaram ao comandante de um dos batalhões. Foram para logo conduzidos à presença do comandante-em-chefe, na comissão de engenharia.

\section{Antônio, o Beatinho}

Um deles era Antônio, o Beatinho, acólito e auxiliar do Conselheiro. Mulato claro e alto, excessivamente pálido e magro, ereto o busto adelgaçado. Levantava, com altivez de resignado, a fronte. A barba rala e curta emoldurava-lhe o rosto pequeno animado de olhos inteligentes e límpidos. Vestia camisa de azulão e, a exemplo do chefe da grei, arrimava-se a um bordão a que se esteava, andando. Veio com outro companheiro, entre algumas praças, seguido de um séquito de curiosos.

Ao chegar à presença do general, tirou tranqüilamente o gorro azul, de listras e bordas brancas, de linho; e quedou, correto, esperando a primeira palavra do triunfador.

Não foi perdida uma sílaba única do diálogo prontamente travado.

- Quem é você?

- Saiba o seu doutor general que sou Antônio Beato e eu mesmo vim por meu pé me entregar porque a gente não tem mais opinião e não agüenta mais.

E rodava lentamente o gorro nas mãos lançando sobre circunstantes um olhar sereno.

- Bem. E o Conselheiro ?. . .

- O nosso bom Conselheiro está no céu ...

\section{Morte de Conselheiro}

Explicou então que aquele, agravando-se antigo ferimento, que recebera de um estilhaço de granada atingindo-o quando em certa ocasião passava da igreja para o Santuário, morrera a 22 de setembro, de uma disenteria,, uma "caminheira" - expressão horrendamente cômica que pôs repentinamente um burburinho de risos irreprimidos naquele lance doloroso e grave.

O Beato não os percebeu. Fingiu, talvez, não os perceber. Quedou imóvel, face impenetrável e tranqüila, de frecha sobre o general, olhar a um tempo humilde e firme. (...) (Cunha, 1963: 456-457).

Um dos pontos de ligação de Cunha com o Jornalismo Literário contemporâneo é a tentativa de, em lugar de heróis, dar voz às pessoas comuns, com seus problemas e limitações. É o que faz outro jornalista que se sucede no tempo a Cunha, João do Rio (1881-1921). Pseudônimo mais famoso de Paulo Barreto, por meio de suas crônicas, como as contidas nos livros $A$ alma encantadora das ruas, o jornalista registra a fenomenal transformação que a então capital brasileira vivenciava. Ou outras, que continuam semelhantes, como o mercado editorial brasileiro:
Um dos pontos de ligação de Cunha com o

Jornalismo Literário contemporâneo é a tentativa de, em lugar de heróis, dar voz às pessoas comuns, com seus problemas e limitações 
Exatamente na esquina do teatro São Pedro, há dez anos, Arcanjo, italiano, analfabeto, vende jornais e livros. É gordo, desconfiado e pançudo. Ao parar outro dia ali, tive curiosidade de ver os volumes dessa biblioteca popular. Havia algumas patriotadas, a Questão da bandeira, o Holocausto, a D. Carmem de B. Lopes, a Vida do mercador e de Antônio Pádua, o Evangelho de um triste e os Desafogos líricos. Estavam em exposição, cheios de pó, com as capas entornadas pelo sol.

— Vende-se tudo isso?

— Oh! Não. Há quase um ano que os tenho. Os outros sim: modinhas, orações, livros de sonhos, a História da princesa Magalona, o Carlos Magno, os testamentos dos bichos...

Levantei as mãos para o céu como pedindo testemunho do alto. As obras vendáveis ao povo deste começo de século eram as mesmas devoradas pelo povo dos meados do século passado!

- Mas não é possível!

- Pode pergunta aos outros vendedores.

Atirei-me a esse inquérito psicológico. Os vendedores de livos são uma chusma incontável que todas as manhãs se espalha pela cidade, entra em casas comerciais, sobe aos morros, percorre os subúrbios, estaciona nos lugares de movimento. Há alguns anos, esses vendedores não passavam de meia dúzia de africanos, espaçados preguiçosamente como o João Brandão na praça do Mercado. Hoje, há de todas as cores, de todos os feitios, desde os velhos maníacos aos rapazolas indolentes e aos propagandistas da fé. (...) Os mais atilados, os mais argutos, os mais são incansáveis são os vendedores de bíblias protestantes, com os bolsos das velhas sobrecasacas ajoujados de brochuras edificantes (Rio, 1997: 136-137).

\section{Novo Jornalismo e revista Realidade}

Nenhuma introdução ao Jornalismo Literário ficaria completa sem a menção a dois ícones da área. O primeiro é o Novo Jornalismo, corrente jornalística que teve alta visibilidade nos Estados Unidos dos anos 1960. Os escritos de Norman Mailer (19232007), Truman Capote (1924-1984) e Gay Talese (nascido em 1932, aos 76 anos está trabalhando atualmente num livro baseado em seu casamento de 50 anos, previsto para ser lançado no outono de 2011) para revistas como The New Yorker e Esquire, bem como livros, influenciaram jornalistas de todo o mundo.

Nascido em 1931, Tom Wolfe é outro expoente do movimento - ele vive com sua esposa Sheila em Nova York. Doutor em Estudos Americanos por Yale, uma das cinco principais universidades norte-americanas, Wolfe se tornou uma espécie de pensador do movimento ao lançar Radical Chique e o Novo Jornalismo. Na obra ele define os quatro principais recursos literários emprega-
Os escritos de Norman Mailer, Truman Capote e Gay Talese para revistas como The New Yorker e Esquire, bem como livros, influenciaram jornalistas de todo o mundo 
dos pelos jornalistas literários: construção cena a cena, diálogos, ponto de vista de terceira pessoa e detalhes simbólicos do status de vida do indivíduo.

Ponto importante é que, apesar da notoriedade atingida por estes e outros escritores durante os agitados anos 1960, outros profissionais já faziam Jornalismo Literário nos Estados Unidos, como Lilian Ross, autora de Picture (Filme, Cia das Letras) e Joseph Mitchell (O segredo de Joe Gould, Cia das Letras) com qualidade notáveis. Filme, por exemplo, narra como um romance a história da filmagem de The Red Badge of Courage (A glória de um covarde), do diretor John Huston, sendo, portanto, um precursor da categoria de romance de não-ficção que anos depois Truman Capote afirmaria ter inventado (o autor, aliás, declaradamente se inspirava em Ross).

No Brasil, a revista Realidade e o Jornal da Tarde são sempre citados como os expoentes máximos dessa onda de Jornalismo Literário nos anos 1960. Realidade, da Editora Abril, chegou a tirar 500 mil exemplares por mês graças à competência de profissionais como José Hamilton Ribeiro, Sérgio de Souza (19352008), Narciso Kalili, Luiz Fernando Mercadante, Roberto Freire e do redator chefe da fase inicial da revista, Paulo Patarra (1933-2008). O período áureo da revista Realidade é de 1966 , quando nasce, a 1968, quando em 15 de novembro é promulgado o Ato Institucional no. 5. Apesar de outros fatos que podem ter contribuído para o fim da revista em 1976, como a criação da revista Veja pela Editora Abril e a mudança de direção da revista imposta por Roberto Civita, parece inegável que, sem liberdade de imprensa não é possível fazer reportagens com a profundidade e amplitude social como Realidade fazia.

José Hamilton Ribeiro, hoje repórter do Programa Globo Rural, da TV Globo, ganhou em 1967 o primeiro de seus sete prêmios Esso pela reportagem $A$ vida por um rim:

Válter Mendes de Oliveira ia morrer: seus rins não funcionavam mais. Médicos do Hospital das Clínicas de São Paulo o submeteram então — era a primeira vez no Brasil - a uma das mais difíceis operações que cirurgiões do mundo inteiro vêm tentando.

Válter Mendes de Oliveira, 41 anos, três filhos, sócio de uma torrefação em São Paulo, é bastante cuidadoso com a saúde. Ele já andou bem ruim e agora tem suas cautelas. Logo cedo, na hora do café, toma a sua pílula diária. É um remédio caro que vem do exterior e que só seis pessoas no Brasil usam.

— Quando me levanto já pago três contos por minha vida.

Se acontece de furar um pneu quando ele está sozinho no carro, não troca: pede ajuda. Muita gente estranha aquele homem com quase 70 quilos, cheio de saúde, pedir que lhe troquem o pneu. Porém, todos 
ajudam de boa vontade quando ele explica a razão: tem um rim só. Mas não é por isso que Válter não troca pneu.

- É por causa dos 98 pontos que eu tenho na barriga. Evito qualquer esforço para impedir uma hérnia. Só pelo rim eu arrastava até um caminhão.

Válter é católico, mas desses católicos que acham que Deus não deve ser incomodado com pedidos pessoais. Por isso, quando foi para o hospital receber os 98 pontos, e - na opinião de sua família - morrer durante aquela operação que nunca tinha sido feita na América Latina, não fez nenhuma promessa. Mas não pôde impedir que outros fizessem por ele. E teve de pagá-las, depois. A primeira, feita por um amigo baiano, era subir a escadaria da igreja do Bomfim, em Salvador. Outra, acompanhar descalço a procissão de São Benedito, em Parati. Velas do seu tamanho, já mandou mais de 100 para Aparecida do Norte. Só falta uma promessa, idéia de um parente lusitano: beijar a imagem da Virgem, em Fátima, Portugal (Ribeiro, 2006: 27-28).

\section{Jornalismo Literário na visão de Mark Kramer}

Uma vez começada, dificilmente se interrompe a leitura de um texto com a abertura acima - Válter ia morrer...-, que convida o leitor a mergulhar na narrativa. Por falar em imersão, a do autor na realidade é a primeira das oito características apontadas por Mark Kramer, co-autor de Literary Journalism (Ballantine

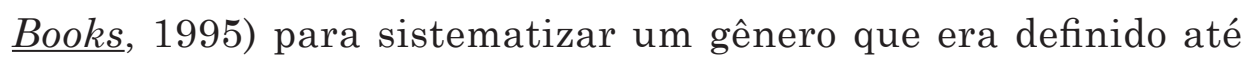
pouco tempo mais ou menos como você-sabe-que-é-JornalismoLiterário-quando-você-vê, como diz o autor. Em entrevista à autora em 2006, Moisés Rabinovici, atual diretor do jornal paulista Diário do Comércio, correspondente de guerra de O Estado de S. Paulo por décadas e participante da fase inicial do Jornal da Tarde, define essa imersão como "escrever com a pele, começando o texto pelo fato mais recente ou que mais tocou o profissional".

Esse mergulho na realidade, que tem como um dos alvos um alto nível de exatidão de informação, demanda muita pesquisa e familiaridade com a temática. A repórter especial Eliane Brum, da revista Época, lembra uma vez em que estava cobrindo o enterro de uma pessoa empobrecida. $\mathrm{O}$ calor era intenso e sobre o muro do modesto cemitério um sabiá parou de cantar justamente na hora em que o caixão foi colocado na cova. $\mathrm{O}$ fato foi registrado pela jornalista não porque complementava com perfeição a cena, mas por ter acontecido. Para registrá-lo, a repórter teve de estar presente no local, acompanhar o funeral, ter sensibilidade para notar as tramas paralelas e, claro, ter bagagem cultural que permitisse identificar a espécie que estava a silenciar.

A apuração precisa, segundo Kramer, também implica a questão ética do autor tanto com o leitor quanto com a fonte - afinal há apurações que levam um longo período de tempo para serem
A apuração precisa também implica a questão ética do autor tanto com o leitor quanto com a fonte - afinal há apurações que levam um longo período de tempo para serem feitas, o que pode gerar bastante vinculação pessoal 
feitas, o que pode gerar bastante vinculação pessoal. Em ambos deve ficar claro que o jornalista está no local como um profissional, não sendo nem inimigo nem amigo, mas uma testemunha da realidade. Essa atuação ética é segunda característica apontada por Kramer.

Para fazê-la, o jornalista deve deixar claro seu método de trabalho. Isso demanda uma conversa prévia na qual expõe a duração prevista da apuração, o enfoque e eventual tamanho da matéria, onde será publicada, se ouvirá outras pessoas e pretende ou não compartilhar o texto antes da publicação, bem como o impacto que imagina que a cobertura pode causar na vida daquela pessoa ou comunidade - ou seja, deve haver transparência no relacionamento com a fonte para que ela possa, inclusive, recusar o convite para participar. Jornalismo Literário pede acesso fácil e constante à fonte para gerar a familiarização necessária, daí os eventos rotineiros serem um campo fértil e inesgotável para boas pautas.

Kramer lembra também o pacto entre leitor e jornalista. Estamos no campo da realidade e ainda que o profissional reconstrua o que se desenrola de acordo com sua bagagem sociocultural, o leitor espera que o jornalista seja honesto o suficiente para relatar o que vê. Caso contrário, estaria lendo fição ou um livro baseado em fatos reais.

Isso significa não inventar nem alterar nada. Em Jornalismo Literário, quem conta um ponto não aumenta um ponto. Citações e pensamentos, por exemplo, devem ser verificados da forma mais simples que existe: perguntando à fonte.

A terceira característica apontada pelo estudioso americano vai na contra-mão dos jornalismo tradicional contemporâneo, obcecado com manchetes sensacionalistas e celebridades, de preferência internacionalmente conhecidas. Para Kramer, jornalistas literários devem prestar atenção e escrever sobre acontecimentos rotineiros, lançando luzes sobre fatos que aparentemente passam despercebidos. Em essência, foi o que celebrizou o jornalista alemão Günther Wallraff. Para escrever Cabeça de Turco, seu livro mais famoso, o jornalista nascido em 1942 se disfarça de turco para sentir na pele os preconceitos e os desafios do subemprego que os imigrantes enfrentam na sociedade alemã.

Voz autoral é a quarta característica proposta por Kramer. Segundo o autor, o jornalista literário tem personalidade. Como pessoa integral que é, pode ter traços tão díspares como intimidade, franqueza, ironia, estranhamento, confusão, até ser julgador ou um tremendo gozador. Aliás, é essa voz íntima que, manifestada de forma mais implícita do que ostensiva, gera um campo de conexão com o leitor. Há personalidades mais fortes, claro. Os textos de Norman Mailer, por exemplo, desmoronam se ele, como 
personagem, for retirado da narrativa. Mas o repórter-degustação, aquele que aparece em primeira pessoa SEMPRE, felizmente parece uma espécie em extinção nos textos mais sofisticados.

Por extensão, estilo é a quinta característica nesse rol. Nesse quesito, o excesso infelizmente é bastante comum. Libertos da pseudocientífica mordaça do jornalismo tradicional, que se pretende imparcial e impessoal, boa parte dos jornalistas que deseja fazer Jornalismo Literário lamentavelmente usa e abusa de uma linguagem artificial e rebuscada. O que é uma pena, pois precisão é uma das grandes vantagens do texto jornalístico. Para evitar esse problema, uma boa idéia é inspirar-se em exemplos reconhecidos, como o texto vigoroso e seco de Ernest Hemingway. Mesmo no de Gabriel García Márquez, mais verborrágico, a leitura atenta evidenciará não haver uma única palavra fora de lugar. Se você prestar a atenção, o mestre colombiano chama essa arte da precisão de carpintaria textual, na qual as palavras são fixadas no lugar certo como a madeira o é com pregos. Em Jornalismo Literário, menos continua sendo mais - mão pesada nunca teve vez entre os leitores.

Na concepção de Kramer, a posição móvel do autor vale ouro no Jornalismo Literário, sendo a sexta característica por ele apontada. Ele está livre da tradicional narração em terceira pessoa para fazer experimentações quanto ao ponto de vista. Aliás, o limite nesse quesito é a competência autoral - e a liberdade não deixa de ser assustadora. Nesse ir e voltar para contar bem uma história, um elemento-chave é a digressão, aquela arte de contar algo indiretamente relacionado para enriquecer a narrativa e voltar ao ponto, findo o desvio. Mas, atenção! Para ser eficaz, esse recurso tem de ser usado nos pontos culminantes da narrativa, como o capítulo de sábado de uma boa novela. Se a digressão estiver no lugar errado, o leitor pára a leitura, vai fazer outra coisa e não volta mais.

A sétima característica é a arte de conferir uma estrutura adequada à história, uma vez que, segundo Kramer, narrativa primária, histórias e digressões se misturam para ampliar e para recompor os fatos. Isso porque se trata de uma forma jornalística principalmente narrativa, isto é, no qual a história é apresentada por meio de cenas que se desencadeiam em seqüencia, como um bom romance.

Finalmente, a oitava característica apontada por Kramer é a criação de sentidos, obtida principalmente com o uso de símbolos e metáforas para facilitar a conexão com o leitor. Todo o trabalho do jornalista é perdido se o leitor não tiver idéia do que ele está falando e, também, se não souber de onde e para onde está sendo conduzido. A história precisa ter um fio condutor e ressoar na experiência pessoal do leitor, que tem de sentir a catarse de chegar a algum lugar depois de ter aceitado acompanhar o protagonista da história por várias cenas, ordenadas de forma a revelar gradativamente a situação.
Libertos da pseudocientífica mordaça do jornalismo tradicional, que se pretende imparcial e impessoal, boa parte dos jornalistas que deseja fazer Jornalismo Literário lamentavelmente usa e abusa de uma linguagem artificial e rebuscada 
Para Kramer, a meta de escrever de forma humana, equilibrada e relevante é encantadora e acessível, porém por vários motivos nem sempre ela é atingida. Por isso, no Brasil, as pesquisas do introdutor dos estudos de Jornalismo Literário, Edvaldo Pereira Lima, sugerem um campo vasto de experimentações. O professor aposentado da Escola de Comunicações e Artes da Universidade de São Paulo e co-criador da Academia Brasileira de Jornalismo Literário (ABJL) batizou de Jornalismo Literário Avançado esse arcabouço conceitual, que além das técnicas citadas incorpora avanços de outras áreas do conhecimento, como a psicologia humanista, a mitologia e a biologia, para facilitar a compreensão e o relato das narrativas da vida real.

\section{Referências}

BALZAC, Honoré de. Eugênia Grandet. São Paulo: Abril Cultural, 1981. CUNHA, Euclides. Os Sertões - Campanha de Canudos. São Paulo: Universidade de Brasília, 1963.

DICKENS, Charles. Retratos Londrinos. Rio de Janeiro: Record, 2003.

LIMA, Alceu Amoroso. O Jornalismo como Gênero Literário. Rio de Janeiro: Agir, 1958.

LIMA, Edvaldo Pereira. Páginas Ampliadas: o livro-reportagem como extensão do jornalismo e da literatura. São Paulo: Manole, 2008.

MARTINEZ, Monica. Jornada do Herói: estrutura narrativa mítica na construção de histórias de vida em jornalismo. São Paulo: Annablume/ Fapesp, 2008.

MEDINA, Cremilda. A arte de tecer o presente - Narrativa e cotidiano. São Paulo: Summus Editorial, 2003.

MITCHELL, Joseph. O Segredo de Joe Gould. São Paulo: Companhia das Letras, 2003.

REMNICK, David. Life Stories - Profiles from The New Yorker. New York: Modern Library, 2001.

RIO, João do. A Alma Encantadora das Ruas. São Paulo: Companhia das Letras, 1997.

SIMS, Normal \& KRAMER, Mark. Literary Journalism. New York: Ballantine Books, 1995.

WOLFE, Tom. Radical Chique e o Novo Jornalismo. São Paulo: Companhia das Letras, 2005. 